\title{
GUNSHOT WOUNDS OF THE CHEST
}

\section{By J. M. FORTESCUE-BRICKDALE}

GunsHOT injuries of the chest necessarily present a varied clinical aspect, according as they are seen at the front, at the base, or in hospitals in England.

Even at the same base, two hospitals may record different experiences, owing to their position as regards distance from the railway station or siding whence patients are transferred by ambulance to the wards. The conclusions and deductions in this paper, therefore, must be understood to apply to a base hospital in France, so situated that severe cases could be prudently sent there, but not so near the railway as some others, and, therefore, not receiving so high a proportion of evidently badly wounded men.

In this hospital 169 cases of injury to the chest came under my care and observation during the last half of the year 1916 .

The following table shows the general classification of these cases, and the gross mortality (3), (7), (8) :

$$
\text { Group. }
$$

\begin{tabular}{rcc} 
Cases. & \multicolumn{2}{c}{ Deaths. } \\
& Number. & $\%$ \\
132 & 6 & $4 \cdot 5$ \\
15 & 3 & 20 \\
89 & 2 \\
23 & 1 \\
5 & 0 & \\
27 & 3 & $2 \cdot 5$ \\
10 & 0 & $11 \cdot 1$ \\
& &
\end{tabular}

The patients were in most cases admitted within a week after the injury, namely :

A. Haemothorax and Pneumothorax

(i) Resected cases

(ii) Large effusions

(iii) Small effusions

(iv) Pneumothorax

B. Laceration or bruising of lung

C. Non-penetrating wounds

Twenty-seven patients were admitted on the day following the infliction of the wound.

On the whole, then, the patients were seen fairly early; there was a fair proportion of severely wounded men among them, but not a large number of heavily infected cases. The proportion of non-perforating wounds is not an index of the number which arrive at the base, as many suffering from severe wounds in other parts did not come under my observation, and others who were only very superficially wounded escaped record in my series.

[Q. J. M., April, IgI8.] 
The following observations were made on cases of penetrating wounds, and have been arranged in sections as follows:

1. Observations on the symptoms, especially haemoptysis and fever, and the physical signs.

2. A note on the associated lung conditions, broncho-pneumonia, collapse, \&c.

3. Complications, both those due to wounds of other internal organs and those due to the lesions inflicted on the lung.

4 and 5 . Certain observations on the pleural fluid and blood.

6. The mortality, showing the death-rate from purely intrathoracic injury.

7. A note on a group of cases, apparently very lightly infected, in which resection was not performed.

8. A comparison between wounds produced by shell fragments and those due to bullets; tables are given showing the factors to which the higher mortality in one class of missile is due, and the peculiar dangers of each.

9. The account of the treatment adopted, and an attempt to show the results of aspiration in the non-infected cases.

Although the series is a comparatively small one, it seemed worth while to work out exact tables and percentages whenever possible, as the cases are typical of a very large group. The numerals in brackets refer to a few statistics given by other writers whose papers were accessible, whenever they could be compared with those in the present series. The references to these will be found at the end of this paper.

\section{Symptoms and Physical Signs.}

Initial symptoms. The histories obtained from patients and in some cases notes sent by medical officers at the front showed that the initial symptoms were collapse, which is variable, not always present, and has usually passed off by the time the patient arrives at the base; pain, also a variable feature and depending largely on the situation of the external wound. It affects not only the chest, but also sometimes the flank and abdomen, or the arm on the wounded side. Initial abdominal symptoms may be decidedly puzzling. In 2 cases in my series abdominal section had been performed at the Casualty Clearing Station and nothing abnormal found. The exploration wounds had healed and the patients appeared none the worse. The remaining initial symptoms are more or less shortness of breath (often only on exertion), fever, and haemoptysis.

The last two symptoms will now be discussed in detail.

Haemoptysis, Reliable histories were recorded in 151 cases ; among these it occurred in 117 , or $77 \cdot 4$ per cent. (3) (7). It was said to be considerable in amount in 10. In the cases in which blood or air had escaped into the pleura there was a. history of haemoptysis in 71.1 per cent, and the amount was said to be considerable in 5. In 48 cases, in which the time during which fresh blood was expectorated could be ascertained, it averaged four days. In one or two cases it continued for a week or more. As a rule the amount is trifling and the 
symptom needs no special treatment. Altered blood may, of course, appear in the sputum for a much longer period, but is of no import.

In 1 case haemoptysis did not come on till the third day, and in 1 it appeared on the first and third days. In 2 cases in which it had ceased it reappeared while the patients were being conveyed to the base on the ambulance train (fifth and sixth days respectively), but was not severe.

In 27 cases diagnosed as laceration or bruising of the lung, in which there were no signs of haemothorax, haemoptysis occurred in all. It continued on an average for three days, and was said to be considerable in amount in $\mathbf{5}$.

Fever. Febrile symptoms are present in the large majority of cases. Some of the cases in this series showed no fever during the time under observation, but may have had a day or two's fever before arrival at the base. There were 17 cases of sterile haemothorax, uncomplicated by other wounds or by inflammatory intrathoracic conditions in which the duration of the fever could be determined.

The average was 10 days, the maximum 23, and the minimum 2 .

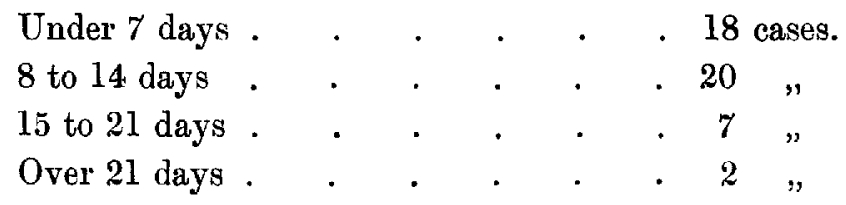

In 8 resected cases, with no complicating wounds or lesions elsewhere, in which the temperature fell during the time the patients were in hospital, the average duration of fever was 49 days, maximum 84, minimum 24 (3) (7).

In 16 cases of 'laceration' of the lung, the fever lasted less than seven days in 13 , and never more than ten days.

In cases in which the fever is short, it is seldom above $100^{\circ} \mathrm{F}$, except perhaps on the day after the wound, and it falls steadily. In more protracted cases it usually remains between normal and $99^{\circ} \mathrm{F}$. in the morning, and $100^{\circ}$ to $101^{\circ} \mathrm{F}$. in the evening. In some cases there are marked oscillations, $99^{\circ} \mathrm{F}$. in the morning, and $102^{\circ}$ to $103^{\circ} \mathrm{F}$. in the evening, and the course is very irregular. Others, again, show a low type of irregular fever with only a degree of variation for more than a week.

Physical signs. The physical signs of haemothorax are usually quite distinctive and need no special comment. They may be confirmed by X-ray examinations and exploratory puncture. Signs of overaction in the unaffected portions of the lungs may often be found. Harsh compensatory breath-sounds may be observed over the front of the chest on the affected side, and in front or behind on the opposite side. The resonance in front of the chest is sometimes increased either on the side of the haemothorax or on the opposite side, and the praecordial dullness and cardiac impulse may be obliterated or very difficult to determine.

In 2 cases $I$ observed on the eleventh and thirteenth days respectively a short puff at the end of expiration, occurring about the middle of the back on 
the affected side. It suggested a small localized cavity in the pleura, communicating with the lung.

The presence of Grocco's paravertebral triangle of dullness was not systematically determined. It was noted as present in 12 cases, in 3 of which there was only a small amount of blood effused.

In 18 cases of pneumothorax or pneumo-haemothorax the physical signs occurred as follows :

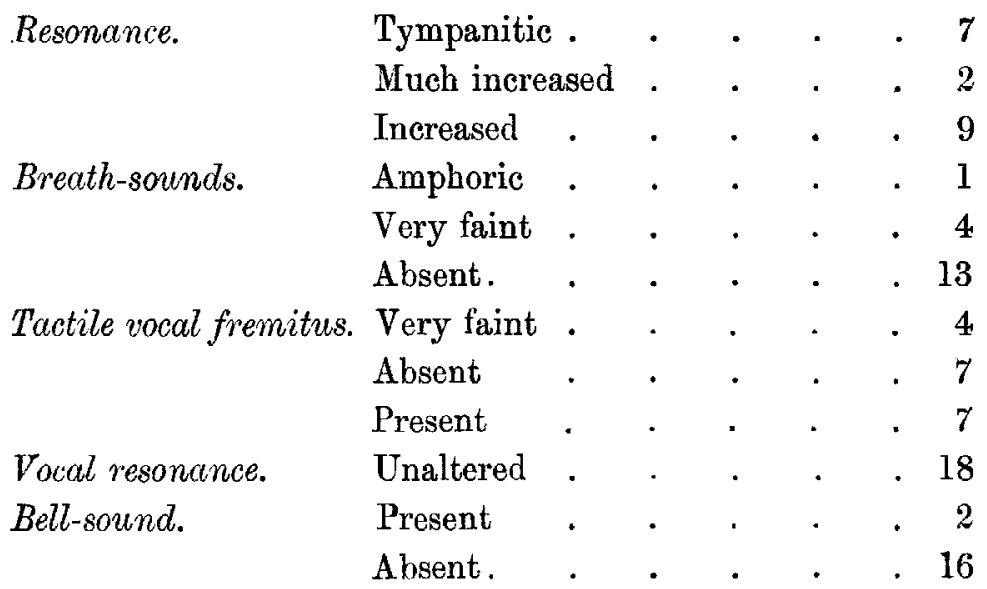

The last-named sign was also present in one case after a considerable amount of oxygen had been run in to replace a baemothorax.

In 10 cases the physical signs were not distinctive, but on aspiration air mixed with blood was evacuated.

\section{Associated Lung Conditions.}

In 1 case there was a history of severe bronchitis with muco-purulent expectoration. The physical signs of bronchitis of a mild type were observed in 20 cases. Cough and expectoration were common. In 6 cases the bronchitis was associated with signs of pleurisy, in 19 pleurisy occurred alone. In 2 of these there was pleuritic effusion.

Case 1. Admitted on the third day after a perforating rifle-bullet wound of the left chest. Ninth day : $17 \mathrm{oz}$. of blood aspirated. Eleventh day : rise of temperature and left-sided pleurisy. Fourteenth day: signs of pleural effusion, which two days later broke through the old exit wound made by the bullet. It was not purulent at first, but infection rapidly occurred, necessitating resection.

Case 26. Admitted on fifth day after penetrating ritle-bullet wound of right chest. Twelfth day : aspirated-a large amount of air and some clear serous effusion withdrawn.

The physical signs disappeared with the exception of poor air entry at the right base by the twenty-first day. Temperature fell by lysis, becoming normal on the sixteenth day.

Pneumonia or broncho-pneumonia occurred in 3 cases. One was a case of general septic infection and ended in death (see Appendix, Case 14). 
The two other patients recovered. In one the pneumonia affected the side opposite the haemothorax (which had been aspirated), and began on the twelfth day after the wound. In the other a rifle bullet had entered the chest without producing a haemothorax; a severe type of septic pneumonia supervened, affecting both lungs, and the temperature did not become normal till the thirtythird day.

One case of gangrene of the lung, without haemothorax, occurred and was fatal (see Appendix, Case 158).

Breath-sounds may be noticed to be weak in the front of the chest on the same side as the haemothorax or at the base on the opposite side. In 18 of the cases in this series there were definite signs of collapse of the lung. The following showed an alteration in the physical signs during its course. In the rest they remained the same in character throughout.

Case 138. Admitted on fourth day after revolver-bullet wound in third intercostal space, anterior axillary line on the right side. Seventh day: dullness, bronchial breathing, diminished vocal fremitus, and vocal resonance over the right base behind. Eighth day: no breath-sounds heard over the lower part of the dull area. Soft breath-sounds over the upper part. Twelfth day: physical signs cleared up. 'Temperature normal throughout.

11 of these cases occurred during the first week and 7 during the second. No signs of collapse were observed later than the thirteenth day.

The wound was near the diaphragm in $6(6)$ cases, not near the diaphragm in 12. In 10 collapse occurred on the same side as the wound and in 8 on the opposite side.

$\begin{array}{cccc}\text { Wound on R. side. } & & \text { Wound on L. side. } \\ \text { Collapse on same side } & \text {. } & 8 & 2 \\ " \quad \text { opposite side } & \text {. } & \mathbf{5} & 3\end{array}$

The cardiac impulse was not observed to be drawn over towards the collapsed side in any of these cases, but in 2 it was pushed over towards the opposite side. The reason for this is not apparent.

Case 130. Admitted on first day after a shrapnel wound on the right side of the back. Slight initial haemoptysis. Third day: dullness, absent. Vocal fremitus and very faint breath-sounds over the right base. Cardiac impulse and dullness just beyond the nipple line in fifth space. Eighth day : right base and heart normal, no sign of haemothorax by X-ray examination, diaphragm moving normally, no cardiac displacement.

Case 141. Admitted on first day after a shrapnel wound over the right shoulder. Exit wound in mid-dorsal region over the spine. Third day : poor note and very weak breath-sounds at the right base. Cardiac impulse and dullness in nipple line fifth space. X-ray examinations showed no signs of haemothorax. Temperature normal.

Congestion. In 4 cases there were physical signs of congestion at the base of the lung, without fever or other inflammatory phenomena. In 3 the physical signs were at the left base, the wounds being on the right side of the chest. In 2 a haemothorax was present. The signs were found on the sixth or seventh 
day and lasted from three to seven days. In the fourth case the wound was on the left side; there was no haemothorax, and no fever after the first day. Dullness, râles, and poor air entry were observed at both bases on the third day, and the physical signs cleared up by the twelfth day.

\section{Complications.}

Jaundice was observed in 2 cases.

Case 3. Admitted on the second day after a shrapnel wound of the right chest with a large haemothorax. The projectile was not seen either above or below the diaphragm by the X-rays. Fifth day: slight jaundice and urticaria. The jaundice deepened till the eighth day, after which it gradually faded. The liver was explored under an anaesthetic, but nothing was found. The haemothorax was reported infected with streptococci, and subsequently a rib was resected.

Case 125. In this case there was an anaerobic infection and wound of the liver. The patient died (see Appendix, Case 125).

The following case came under my observation at another time and is not included in the series:

The patient was admitted on the fifth day after a shrapnel wound of right chest, a wound below the costal margin on the right side of the back, and a deep lacerated wound of the right thigh. X-rays examinations showed a shrapnel ball lying superficially near the second right costal cartilage and fragments of shell-casing in the right lung one inch above the diaphragm. There were physical signs of fluid at the right base, but only a slight shadow. Clear, slightly blood-stained fluid was withdrawn and found to be sterile. Eighth day : slight epistaxis. Ninth day : severe and continued vomiting. Slight jaundice, no bile pigments in the urine. Tenth day: still vomiting. Jaundice deeper. Patient very weak and ill. Eleventh day: less vomiting. No bile pigments in urine. Twelfth day : patient became collapsed and died in the afternoon. Post-mortem : localized suppurative pleurisy under the bullet. Pleural effusion over base of right lower lobe. The missile entering at the wound in the back had wounded the right kidnoy, but not the liver.

The jaundice, therefore, is not the result of gross damage to the liver, but is of the toxic type.

Abdominal injuries. Occurred in 3 cases, and were fatal (see Appendix, Cases 15, 125, 157).

In 2 cases the liver was wounded but the patient survived. In one there was a discharge of bile from a wound in the right side, which ceased after a few days; in the other a foreign body was seen by the X-ray embedded in the liver, but gave rise to no symptoms.

Lesions of the nervous system were noted in 4 cases. In 2 the spinal cord was damaged, producing paraplegia; in 2 there were peripheral nerve injuries producing paresis of the right arm.

Haematuria occurred in 1 case.

Case 29. Admitted on the fourth day after a shrapnel-bullet wound which had entered the chest near the angle of the tenth rib on the left side, and passing 
upwards had left it at a point over the fourth intercostal space, about two inches outside the nipple line. Haemothorax present and aspirated. Staphylococci found in the pleural blood. Tenth and eleventh days: haematuria. A catheter specimen was found to be normal in other respects and sterile. Fourteenth day: temperature $101.4^{\circ} \mathrm{F}$. Fifteenth day : temperature fell to normal. No further symptoms. ${ }^{1}$

It is difficult to see how the bullet could have wounded the kidney, and, even if it did, why the haemorrhage oceurred on the tenth day (8).

Subcutaneous emphysema was noted in 21 cases. In 9 it was small in extent, moderate in 6 , and extensive in 4 (in 2 cases the projectile did not appear to have penetrated the thorax); in 2 cases it was very extensive. The symptoms cleared up rapidly (3).

Secondary haemorrhage. In 6 cases in which a haemothorax was aspirated on the second or third day, there was evidence that further bleeding may have occurred in one instance.

(i) Admitted collapsed to a Casualty Clearing Station and $26 \mathrm{oz}$. aspirated on the next day. Transferred to the base on the seventh day with signs of a large haemothorax. 64 oz. aspirated on the tenth day. The fluid was thick, of a reddish-brown colour, showed no distinguishable cells under the microscope, and was sterile.

(ii) Aspirated at a Casualty Clearing Station eighty-four hours after being wounded. Transferred to base on the ninth day with signs of a large haemothorax. 24 oz. aspirated on the fifteenth day. The fluid was thin and bloodstained, showed sedimentation, but did not coagulate. It contained endothelial plaques, but no recognizable blood-cells, and was sterile.

(iii) 49 oz. aspirated at a Casualty Clearing Station on the third day. Transferred to base on the eighth day, when physical signs were so slight that no further aspiration seemed necessary.

(iv, v) Two cases aspirated at the base on the third day without signs of reaccumulation.

(vi) 36 oz. aspirated at the base on the second day. Cardiac impulse then found to be one inch outside the nipple line. Fifth day: cardiac impulse one inch inside the nipple line. Eleventh day: cardiac impulse again one inch outside the nipple line. Fourteenth day: cardiac impulse returned to nipple line. The physical signs over the right base remained unchanged throughout.

In the first 2 cases the blood was altered, and there was no evidence that bleeding had occurred after the primary puncture. In the third, fourth, and fifth no bleeding of any consequence can have occurred. In the sixth it seemed probable that further haemorrhage took place, but it ceased fairly soon, as on the nineteenth day only $10 \mathrm{oz}$. could be withdrawn owing to clotting.

1 The subsequent history obtained by the Medical Research Committee gave no indication of a recurrence of the haematuria, and the patient returned to duty $2 \frac{1}{2}$ months after he was wounded. 


\section{Character of the Pleural Fluid.}

The fluid withdrawn from the pleura by aspiration varies in appearance from what seems like normally clotting blood to a thick brownish-red fluid, from which a deposit forms on standing, leaving a bright yellow serum. In these specimens clotting is absent or very slow and imperfect. In other cases a thin blood-stained serum is withdrawn. Effusions infected with anaerobic organisms have a characteristic unpleasant odour.

In 4 specimens from which anaerobes were isolated the following characters were noted. In 1 the fluid was thin and coagulated rapidly, in 3 others it deposited a thick sediment and clotted incompletely or not at all. One aspirated on the third day showed 64 per cent. polynuclear cells; a second, in which there was a mixed infection of anaerobes and cocci, showed an excess of polynuclear cells on three occasions. The remaining 2 showed almost entirely lymphocytes.

In 5 specimens infected by various cocci in which the behaviour of the fluid as to clotting was noted, in 4 coagulation took place imperfectly or slowly, and in 1 it was rapid. In 9 specimens, all but 1 showed an excess of polynuclear cells; the remaining 1, explored on the eighth day, showed only a few lymphocytes and no other cells.

In 20 specimens which were found to be sterile clotting was noted in 2 cases as rapid; in 6 others it was imperfect or absent, often with sedimentation. In those aspirated during the first nine days, polynuclear cells were in considerable excess in 8 , and in 8 more constituted about 50 per cent. of the total. In 7 the lymphocytes were considerably in excess. On the other hand, in the specimens taken from patients aspirated from the tenth to the twentieth day lymphocytes were in excess in 5 and in equal numbers to the polynuclears in 2 ; in none was there an excess of polynuclear cells.

Cells in proportion of $50 \%$ and upwards Polynuclears Lymphocytes

4 th to 9 th day

$70 \%$ of specimens

$30 \%$ of specimens
10 th to 20 th day

$30 \%$ of specimens

$70 \%$ of specimens

Endothelial cells were noted in 37 out of 63 specimens in varying numbers, which bore no apparent relation to the infection or non-infection of the pleural fluid, or to the date after the injury on which the specimen was obtained.

\section{Blood Counts.}

Differential leucocyte counts were made in a few cases (19).

In 7 cases of haemothorax without complicating factors (such as other wounds or chest affections) there was a relative increase in the small lymphocytes and a decrease in the polynuclear cells towards the end of the first week, together with a decided increase in the eosinophil cells, and a less marked increase in the basophil granular cells. In two cases of infected haemothorax, which were subsequently resected, these features did not appear to the same extent, and were later in developing. 
In a case of non-penetrating wound of the chest, which was examined as a control, these changes could not be traced. In one of the cases where the eosinophilia was excessive the patient developed at the same time an urticarial rash, which was attributed to the antitetanic serum. All the patients had received one dose of serum on the day of the wound.

\section{Averages of Blood Counts.}

Grovp I. Infected Haemothorax.

Polynuclear

Lymphocytes

Transitionals

Large mononuclear

Total mononuclear

Eosinophils

Basophils

Day after wound.

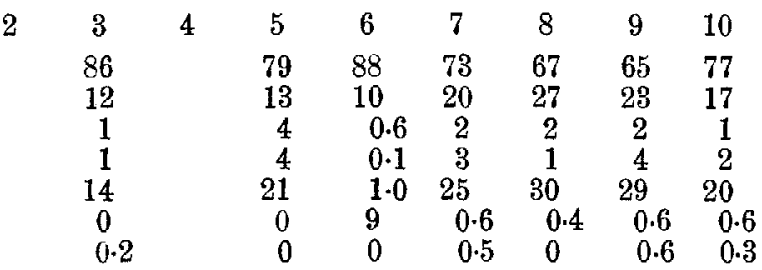

Group II. Non-infected Haemothorax.

\begin{tabular}{|c|c|c|c|c|c|c|c|c|c|c|c|}
\hline & 2 & 3 & 4 & 5 & 6 & 7 & 8 & 9 & 10 & 12 & 15 \\
\hline Polynuclear & 77 & 69 & 64 & 57 & 53 & 61 & 64 & 56 & 60 & 68 & 67 \\
\hline Lymphocytes & 18 & 21 & 24 & 32 & 33 & 30 & 24 & 34 & 29 & 28 & 27 \\
\hline Transitionals & 2 & 2 & 2 & 1 & 1 & 1 & 2 & 1 & 2 & 2 & \\
\hline Large mononuclear & 2 & 2 & 0.6 & 2 & 2 & 1 & - & 2 & 1 & 1 & 1 \\
\hline Total mononuclear & 22 & 25 & 26 & 35 & 36 & 32 & 26 & 37 & 32 & 31 & 29 \\
\hline Eosinophils & 1 & 3.5 & 4.5 & $4 \cdot 6$ & 4.6 & $6 \cdot 2$ & $5 \cdot 4$ & $4 \cdot 6$ & 4.1 & 1.8 & \\
\hline Basophils & 0 & 0 & $0 \cdot 3$ & 0.1 & 0.6 & 0.3 & $0 \cdot 1$ & $0 \cdot 4$ & 0.8 & $0 \cdot 4$ & \\
\hline
\end{tabular}

Control Case. Non-penetrating wound.

Polynuclear Lymphocytes Transitional

Large mononuclear Total mononuclear Eosinophils Basophils

$\begin{array}{ccccccc}3 & 4 & 5 & 6 & 7 & 8 & 9 \\ 65 & 66 & 73 & 67 & 66 & 69 & 71 \\ 33 & 29 & 23 & 29 & 32 & 28 & 24 \\ 0.5 & 2 & 1 & 1 & 1 & 1 & 1 \\ 1 & 0 \cdot 8 & 1 & 2 & 0 \cdot 6 & 1 & 2 \\ 33 & 31 & 25 & 32 & 33 & 30 & 27 \\ 0 & 0 \cdot 6 & 1.0 & 0.7 & 0.4 & 0.3 & 0 \cdot 1 \\ 0 & 0 & 0 & 0 \cdot 3 & 0 & 0 & 1\end{array}$

The remaining cases have not been quoted, as in some complicating factors were present, and in others the counts wero not systematically made over a sufficient number of days.

\section{Mortality.}

The gross mortality of 159 penetrating wounds of the chest was 9 , or 5.6 per cent., but not all of these patients died of thoracic injuries. In 2 cases with haemothorax there were severe concomitant abdominal injuries, and in 2 cases without haemothorax there was a severe abdominal injury in one, and a septic meningitis in the other. In 1 case of haemothorax the external wound was infected by gasproducing organisms. The deaths, therefore, which were attributable to purely intrathoracic injuries were 4 in number, or 2.5 per cent. of the total number of cases. This includes one patient who died of septic pericarditis and pleurisy. 


\section{Group.}

A. Haemothorax and pneumothorax

(i) Resected cases

(ii) Large effusions

(iii) Small effusions

(iv) Pneumothorax

B. Laceration or bruising of the lung
Cases.

132

15

89

23

77
Deaths.

$\begin{array}{cc}\text { Number. } & \% \\ 4 & 3 \\ 2 & 13 \cdot 3 \\ 1 \\ 0 \\ 0 \\ 1 & 0.8 \\ & 3.7\end{array}$

All the 9 deaths which occurred in the entire series except 1 were due to septic infection. 4 were caused by anaerobes, 1 by a number of organisms of which the pneumococcus was the predominant, and in 2 the causal organism was not determined. In the 1 case in which sepsis was not a factor the patient died of intra-abdominal haemorrhage.

In 20 severely infected cases there were four (8) (3) (7) deaths from purely intrathoracic causes ( 20 per cent.).

Short notes of all the fatal cases will be found in the Appendix.

\section{Lightly-infected Cases.}

In 29 cases organisms were grown from the blood, but resection was not performed in France. The organisms were:

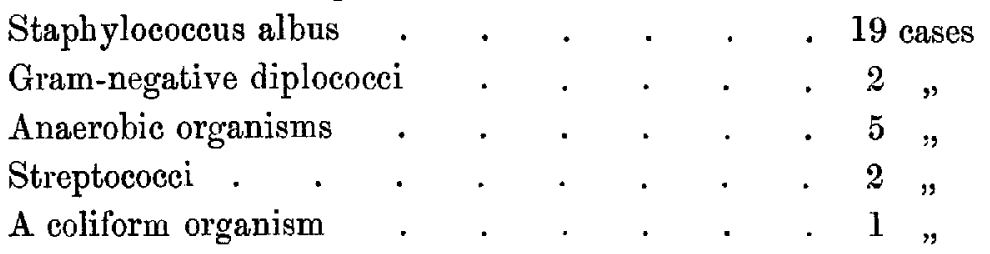

1. Staphylococcus albus. In 9 cases the absence of fever and of general symptoms made it appear that the organism was only an accidental contamination. In 2 others complications accounted for the fever, which subsided when these were dealt with. The after-history of 9 out of the 11 cases was traced by the Medical Research Committee in England, and in no case was there any record of further operations on the chest. Seven had roturned to duty either in France or at their depôts at the time of the inquiry.

In 8 of the cases there were more pronounced symptoms, suggesting an infection of the pleural fluid.

In 2 there was a slight rise of temperature about the tenth day after the wound; both these cases were aspirated in France. The Medical Research Committee's report on the after-history of 1 showed that no further treatment for the chest condition was necessary, and that the patient remained in hospital $2 \frac{3}{4}$ months in all before returning to duty. The other case was still in hospital eleven months after the wound, but no medical case-sheet could be obtained.

In 2 cases the fever lasted sixteen and eighteen days respectively, but was never high, and fell steadily without much oseillation. Both were explored twice, but only a small amount of blood was withdrawn. They remained in hospital in England for about one month and were discharged to duty without further operations on the chest. 
In the remaining 4 cases the temperature remained high for a considerable period. The charts of these cases are appended (Charts 1 to 4 ).

(i) 'Thirty-two days' fever of an oscillating type. Aspirated 11 oz. on the fifth day, some air also being withdrawn; on the eighteenth day further exploration. On each occasion the organism was cultivated from the pleural blood. Two tests for enteric agglutinins were made with negative results. There was slight leucocytosis on the twenty-second day (W. B. C. 12,000). The Medical Research Committee's report showed that he was discharged from the army as unfit after a total of four months in bospital, but there was no record of any subsequent operation on the chest in lingland.

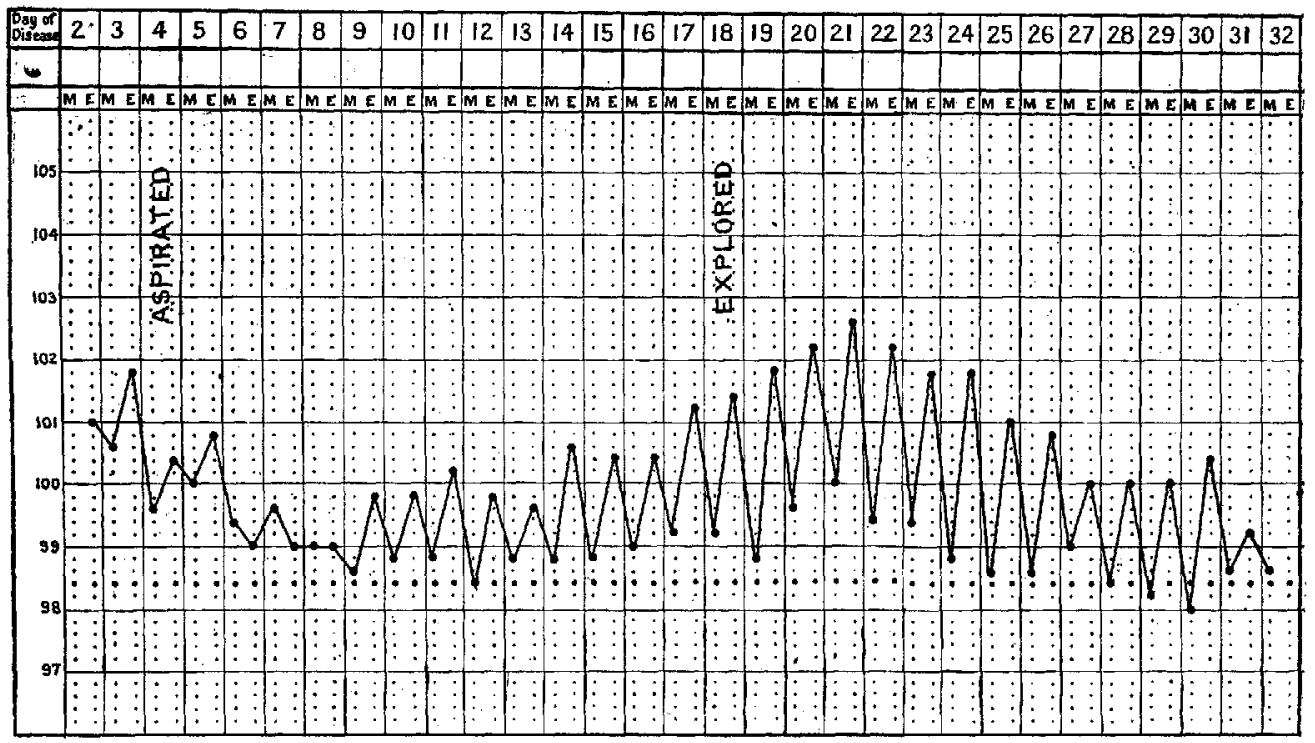

Chart 1 (Case 38).

(ii) Fifty days' fever of an oseillating type. Aspirated 24 oz. on the sixth day. Explored at various points on the chest on the sixteenth and nineteenth days, without aspiration. On the thirty-sixth day 2 oz. only could be withdrawn. S. albus cultivated on three occasions. The patient's general condition was good throughout, as he slept and ate well, but his mental condition was childish, and several times he had incontinence of urine. Four months after his wound the chest condition was reported as satisfactory; there had been no return of fever, but his mental condition was unchanged.

(iii) Thirty days' fever. Aspirated $56 \mathrm{oz}$. on the seventh day, and again explored on the twentieth day. The organism was only found once. The Medical Research Committee's report showed that he remained $2 \frac{1}{4}$ months in hospital and was discharged to duty in England without further operation.

(iv) 'Twenty days' fever of an oscillating type. Aspirated $26 \mathrm{oz}$. on the fifth day and $2 \mathrm{oz}$. on the twelfth day. The organism was cultivated from the fluid on both occasions. He was discharged to duty in England after $2 \frac{1}{2}$ months, without further operation.

In these 4 cases the projectile was only retained in the chest in 1 (Case ii).

Gram-negative diplococci. In the 2 cases where these were found the organisms appeared to be merely contaminations. There was no clinical

[Q. J. M., April, 1918.] 


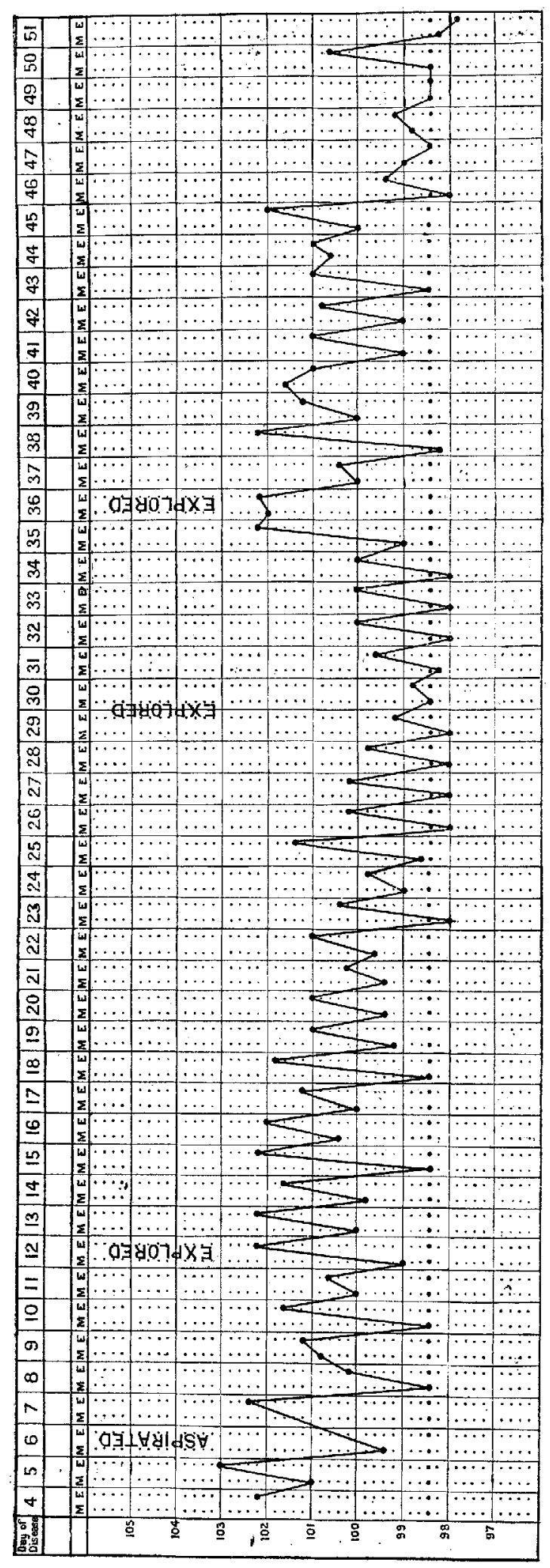

evidence of an infection, and their subsequent history after evacuation to England showed that they were both returned to duty without further symptoms.

Coliform organism. The evidence of infected haemothorax was not at all conclusive, and after evacuation to England the patient was discharged without further operative treatment and was classed fit for general service.

Anaerobes. In these 5 cases only 1 had fifteen days' fever. In 3 the fever was of still shorter dura$\dot{\hat{\theta}}$ tion, and in 1 there was no क् fever at all.

The Medical Research Committee's report showed that all were returned to duty in two to three months without further operation, and that 3 were serving in France.

Streptococci. (i) The patient had an oscillating temperature for three weeks, sometimes reaching $102^{\circ} \mathrm{F}$. in the evening, which fell gradually after each aspiration (eleventh and fourteenth days). Pus cells and streptococci were present on the first occasion, pus cells only on the second. His general condition was fairly good when he was evacuated to England.

(ii) The patient had an oscillating temperature for thirty-three days, mainly apparently due to infection of the external wound. 
Aspiration on the sixteenth day did not affect the course of the fever; streptococci were found in the fluid. When the external wound was opened up the temperature fell; no communication with the pleura was then found.

Unfortunately the after-history of these 2 cases could not be traced (6).

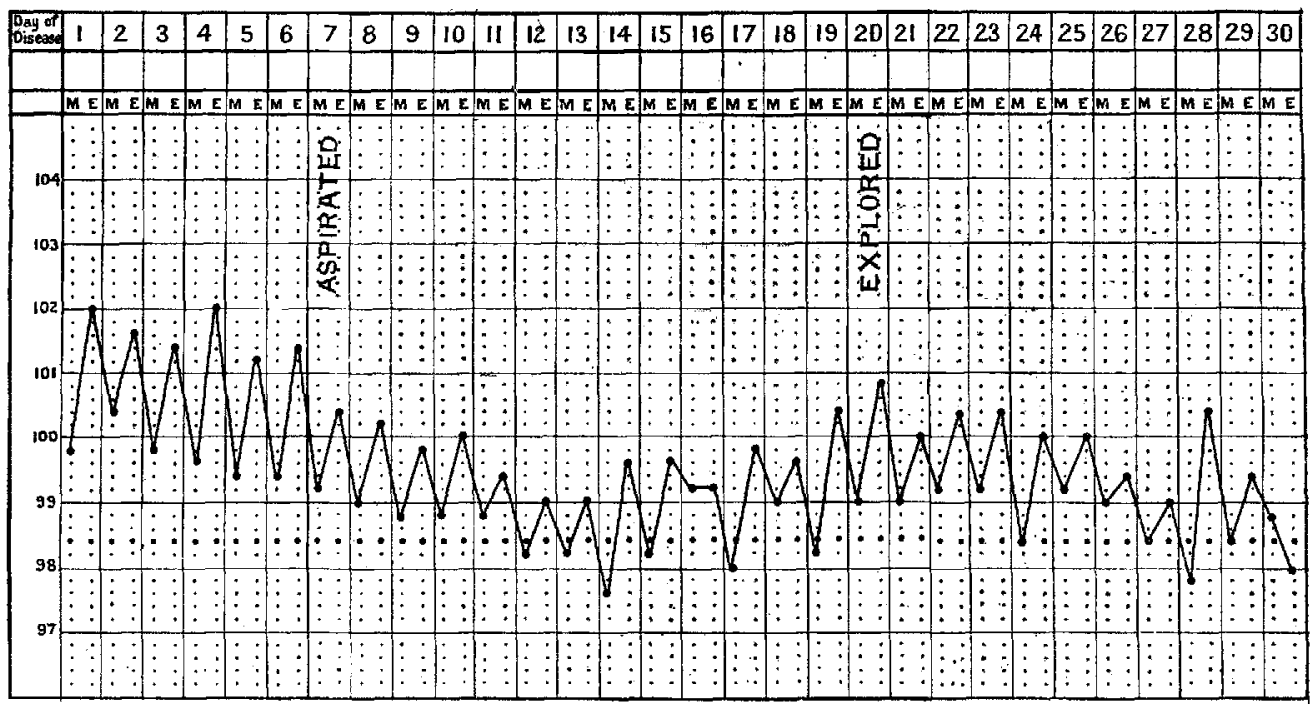

Chart 3 (Case 62).

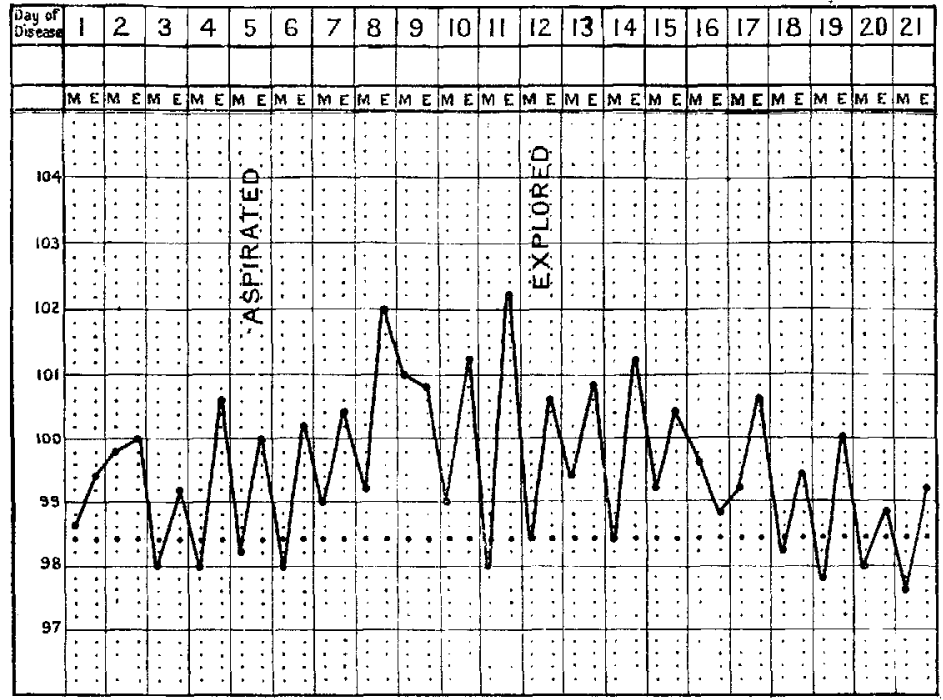

Chart 4 (Case 52).

8. Comparison between Shell-fragment and Bullet Wounds.

In 143 cases of penetrating wounds of the chest the nature of the projectile was ascertained (3).

Bullets, 47 . . . . . . $\quad$. $=32.9$ per cent.

Shell fragments, 95 . . . . $=66 \cdot 4$ "

Aerial dart, 1 . . . . . . $=0.7$ " 
In 47 cases of bullet wound there were two deaths $=4.2$ per cent.

In 93 cases of shell-fragment wound there five deaths $=\mathbf{5 . 3}$ per cent.

In 137 cases the retention or non-retention of the projectile was recorded.

Projectile.

Bullets

Shell fragments
Retained.

Cases. Deaths. \%

71 per cent. of the total deaths in which the projectile was known were caused by shell fragments.

In every 100 cases there will be 4.6 deaths -3.3 due to shell fragments and $1 \cdot 3$ to bullets.

Shell fragments, therefore, are somewhat more fatal than bullets, although bullets more often produce perforating wounds. In 51 cases of perforating wound 29 were due to bullets. The retained bullet is not so fatal as the retained shell fragment, though the bullet which is not retained is more fatal than the shell fragment which is not retained.

This can be explained by a consideration of the separate factors involved.

1. Sepsis. In 14 cases requiring resection (that is, obviously heavily infected), 10 were caused by shell fragments and 4 by bullet wounds, and of 6 deaths from sepsis, 4 were caused by shell fragments and 2 by bullets. In 28 cases of haemothorax in which organisms were grown from the fluid withdrawn by exploration, 23 were due to shell fragments and 5 to bullets. In 12 of these there was presumably a certain degree of sepsis, as the febrilo symptoms were well marked. 8 of the 12 were due to shell fragments, and in 2 the shell fragment was retained.

The following table shows the organisms found and the projectile concerned :

Organism.

Shell Fragments.

Bullets.

\section{Staphylococcus albus Streptococcus Anaerobic organisms}

Totals

$$
\text { Retained. Not retained. }
$$

$\begin{array}{ll}- & 4 \\ \frac{2}{2} & \frac{1}{6}\end{array}$

$\begin{array}{cc}\text { Retained. } & \text { Not retained. } \\ \frac{1}{1} & \frac{1}{1} \\ \frac{1}{2} & \frac{1}{2}\end{array}$

2. Haemoptysis. As a possible indication of the direct damage caused to the lung by the different forms of projectile, the following analysis of the cases showing this symptom was made.

In 114 cases of haemothorax 35 were caused by bullet wounds, 79 by shell fragments, and there were 85 cases of haemoptysis. In a proportion of these the length of time during which the baemoptysis lasted could be ascertained.

\begin{tabular}{|c|c|c|c|c|c|}
\hline \multirow[b]{2}{*}{ Projectile. } & \multicolumn{2}{|c|}{ Haemoptysis. } & \multirow{2}{*}{$\begin{array}{l}\text { Average con- } \\
\text { tinuance in } \\
\text { days. }\end{array}$} & \multirow{2}{*}{$\begin{array}{l}\text { Maximum } \\
\text { duration in } \\
\text { days. }\end{array}$} & \multirow{2}{*}{$\begin{array}{l}\text { Cases in } \\
\text { which con } \\
\text { siderable. }\end{array}$} \\
\hline & $\begin{array}{c}\text { Number of } \\
\text { Cases. }\end{array}$ & $\%$ & & & \\
\hline $\begin{array}{l}\text { Bullets } \\
\text { Shell fragments }\end{array}$ & $\begin{array}{l}28 \\
57\end{array}$ & $\begin{array}{l}79 \cdot 4 \\
72 \cdot 1\end{array}$ & $\mathbf{5} \cdot 8$ & 12 & $\begin{array}{l}1 \\
3\end{array}$ \\
\hline
\end{tabular}


In 24 cases of penetrating wound without haemothorax 8 were caused by bullets and 16 by shell fragments, and haemoptysis occurred in all.

\begin{tabular}{|c|c|c|c|c|c|}
\hline \multirow[b]{2}{*}{ Projectile. } & \multicolumn{2}{|c|}{ Haemoptysis. } & \multirow{2}{*}{$\begin{array}{l}\text { Average con } \\
\text { tinuance in } \\
\text { days. }\end{array}$} & \multirow{2}{*}{$\begin{array}{l}\text { Maximum } \\
\text { duration in } \\
\text { days. }\end{array}$} & \multirow{2}{*}{$\begin{array}{c}\text { Cases in } \\
\text { which con. } \\
\text { siderable. }\end{array}$} \\
\hline & $\begin{array}{l}\text { Number of } \\
\text { Cases. }\end{array}$ & $\%$ & & & \\
\hline $\begin{array}{l}\text { Bullets } \\
\text { Shell fragments }\end{array}$ & $\begin{array}{r}8 \\
16\end{array}$ & $\begin{array}{l}100 \\
100\end{array}$ & $\begin{array}{l}3 \cdot 2 \\
3 \cdot 7\end{array}$ & $\begin{array}{l}9 \\
8\end{array}$ & $\begin{array}{l}2 \\
3\end{array}$ \\
\hline
\end{tabular}

Combining these two tables, bullet wounds cause haemoptysis in 83.7 per cent. of cases, it is considerable in amount in 7 per cent., and continues on an average for four days. Shrapnel wounds cause haemoptysis in 74.7 per cent. of cases, it is considerable in amount in 6.5 per cent., and continues on an average for three days.

3. Duration of fever. The nature of the projectile does not seem to affect the duration of the fever in uncomplicated cases. In 32 cases of sterile haemothorax, the average duration of fever was ten days in the case of both bullets and shell fragments; and in 13 cases of 'laceration' of the lung, the average duration was eight days for bullets and $7 \cdot 6$ for shell fragments.

4. Associated lung conditions. In 48 cases in which some inflammatory condition of the lungs or pleura, giving rise to definite physical signs, was noted, 13 were caused by bullets, 29 by shell fragments, and in 6 the projectile was not ascertained.

\begin{tabular}{|c|c|c|c|c|c|}
\hline \multirow{2}{*}{ Disease. } & \multirow{2}{*}{$\begin{array}{c}\text { Number } \\
\text { of } \\
\text { Cases. }\end{array}$} & \multicolumn{2}{|c|}{ Bullets. } & \multicolumn{2}{|c|}{ Shell Fragments. } \\
\hline & & Number. & $\%$ & Number. & $\%$ \\
\hline Bronchitis & 20 & 5 & 25 & 15 & 75 \\
\hline Pleurisy & 5 & 0 & 0 & 5 & 100 \\
\hline Bronchitis and pleurisy & 15 & 6 & 40 & 9 & 60 \\
\hline $\begin{array}{l}\text { Pneumonia and broncho- } \\
\text { pneumonia }\end{array}$ & 2 & 2 & 100 & 0 & 0 \\
\hline Totals & $\overline{42}$ & 13 & 31 & $\overline{29}$ & 69 \\
\hline
\end{tabular}

5. Leaking wounds. In 7 cases in which there were leaking wounds on admission, 3 were caused by bullets and 4 by shell fragments.

6. Perforating wounds. In 51 perforating wounds, 29 were caused by bullets, 19 by shell fragments, and 3 by projectiles the description of which was unknown. 67 per cent., therefore, of the bullets perforated the chest, and 20 per cent. of the shell fragments.

Summary. Shell fragments are accountable for a somewbat higher mortality than bullets. This is due to the greater likelihood of septic infection. In fivesevenths (71 per cent.) of the resected cases (i. e. those heavily infected) the wounds were caused by shell fragments. 66 per cent. of the cases where a light infection occurred were due to shell fragments, and 57 per cent. of leaking wounds, which are, of course, more liable to infection. 69 per cent. of the cases in which inflammatory conditions in the thorax were observed were due to shell-fragment wounds.

On the other hand, bullets caused a greater number of perforating wounds, and produced more haemoptysis. 
In uncomplicated sterile cases the fever was of the same duration in both classes of wounds.

\section{Treatment.}

Heavily infected cases. When the fluid withdrawn by the exploring syringe is found to contain numerous bacilli, streptococei, or pus cells, the ordinary surgical treatment for an empyema is necessary. In many cases it is not needful to wait for the result of a laboratory examination, as the obvious characters of the fluid, and especially its odour, are sufficient to show that it is septic. At the operation, or at subsequent dressings, clots should be removed and the pleura irrigated. When the projectile is easily accessible, it should, of course, be removed, but extensive operations are not advisable. The following case, however, in which the foreign body was not found while the patient was in France, is instructive :

Case 8. Admitted on fourth day after a shrapnel wound on right shoulder, just over apex of lung. There was a large pneumo-haemothorax on the right side, with much cardiac displacement. The temperature oscillated between $99^{\circ} \mathrm{F}$. and $101^{\circ} \mathrm{F}$. Ninth day : aspiration, only $6 \mathrm{oz}$. of rapidly elotting blood withdrawn. The fever continued and the patient suffered from rather severe joint-pains of a rheumatic type. Thirty-first day : aspiration, 44 oz. of dark brown blood mixed with air. The fever continued and there were indefinite abdominal symptoms. The foreign body was located near the diaphragm, but there was some doubt as to whether it was above or below. Forty-second day: the pleura was opened and a large amount of foul blood and clot removed. The patient's general condition improved and the temperature became normal on the eighty-fifth day. He was evacuated to England, but it was subsequently learnt that on closure of the empyema wound the febrile symptoms returned, and an operation for the removal of the foreign body was undertaken, after which the patient recovered.

In 2 cases of anaerobic infection, attempts were made by repeated aspiration and the injection of oxygen to obviate the necessity for resection. In 1, in which the patient's condition remained fairly good, the chest was aspirated eight times during six weeks, a total of $190 \mathrm{oz}$. being removed. The temperature, however, only fell temporarily after the aspirations, and bacteriological examinations showed that though the anaerobes gradually disappeared from the fluid, Gram-positive diplococci remained and increased in numbers. On the fifty-fourth day resection was performed and the patient made a good recovery. In the second case, the chest was aspirated three times in twenty-six days, a total of $162 \mathrm{oz}$. being removed. On the last occasion the fluid was purulent, and a rib was subsequently resected. The patient, who was extremely ill on admission, made a good recovery.

Lightly infected cases. In this class of case, though organisms are found in the blood withdrawn by exploration of the pleura, the patient's general condition does not suggest a severe infection. These cases may be treated in the same way as those which are bacteriologically sterile, but they require careful watching, and often repeated exploration, as in some the infection becomes more 
severe, definite pus appears in the pleura, and resection becomes necessary. Even where the fever persists for a long time these patients eventually recover, with good functional restoration in the lung, if the organism is a staphylococcus.

Sterile cases. In simple sterile haemothorax the treatment will depend on the size of the effusion and its effects on the position of the heart and the general comfort of the patient. These are not solely dependent on the number of ounces of blood in the pleura; some patients tolerate much larger collections of fluid without obvious inconvenience than others.

It is not necessary to keep the patient absolutely immobilized, though he should of course be kept strictly to bed. Most patients prefer to be propped up for all or part of the time.

Except cases in which an exploratory puncture shows that the blood has clotted and cannot be withdrawn, it is advisable to aspirate about the end of the first week. In 89 cases in which there was evidence of a fair-sized effusion, an average of $26 \mathrm{oz}$. was removed from 64 . The minimum amount was $10 \mathrm{oz}$. and the maximum 76 oz. Of the remaining 25 cases, 1 died of anaerobic infection before any attempt at aspiration could be made, 1 had already been aspirated at a C. C.S. before admission, and 1 was transferred to England without aspiration. In the remaining 22 cases, 10 were cases of pneumo-haemothorax from which air and a small quantity of blood were removed. In the rest, clotting interfered with aspiration; in only 4 of them was it attempted during the first week.

A general anaesthetic was not found

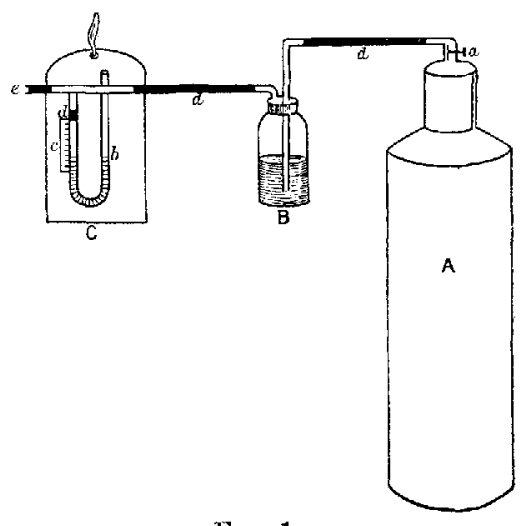

Fic. 1.

A. Oxylite.

B. Wash-bottle containing absolute alcohol.

c. Board on which manometer is fastened.

a. Tap.

b. Manometer.

c. Millimetre scale.

d.d.d. India-rubber tubing.

e. Tubing leading to needle. necessary except in a few cases. The skin was frozen for the insertion of the trocar and cannula. Potain's apparatus was used. Oxygen replacement was adopted in all cases, and seemed decidedly useful. Three or four pints could be removed without coughing or respiratory distress to the patient. The oxygen was generated in a convenient French apparatus known as the 'Oxylite', passed through a wash-bottle containing absolute alcohol, and then over a manometer. The tubing through which it passed was boiled and connected with the apparatus immediately before use. The needle connected with the oxygen tube was of fairly wide bore, and was inserted two or three spaces above the Potain cannula; the oxygen was allowed to flow in at a pressure of not more than 3 or $4 \mathrm{~mm}$. during the aspiration, and sometimes for a few minutes longer. Often some bubbled out with the last 2 or 3 oz. of blood. The advantage of the 'Oxylite' generator is that the 
gas is given off at comparatively low pressure and is easy to control by means of the tap at the top of the cylinder.

The general arrangement of the apparatus is shown in the figure. In 9 cases, small amounts of eusol (10 to 15 c.c.) were injected after the aspiration, but with no appreciable effect on the temperature or other symptoms. A second aspiration was not usually attempted, though in some cases an exploratory puncture was made if the physical signs or fever persisted. In most cases the intrapleural blood had clotted. In 9, however, the pleura was aspirated for a second time. In 5 only a small quantity was drawn off; in 3 one to three pints were removed; and in the last, one pint, after the first aspiration had yielded only a small quantity.

Cases may occur in which there are signs of a large effusion, and yet aspiration fails to draw off the blood. Unless the patient is much distressed, these cases do quite well if left alone, but recover more slowly. If there is much dyspnoea and distress the pleura may be opened under an anaesthetic, the blood and clot turned out, and the opening closed. These cases should not be treated as an empyema.

In one case in this series, where a drainage-tube was inserted, the pleura rapidly became infected and the patient died (Appendix, Case 13) (2).

In this series of cases no attempt was made to recover the foreign body, unless it was easily accessible, either in the chest-wall or the pleura. It seems very doubtful if any real advantage is gained by extensive operations on the lung for the removal of bullets or shrapnel fragments, unless there is a definite evidence that they are septic, and producing abscess or gangrene of the lung. Where there are no signs of this, the foreign body is probably harmless.

The immediate results of aspiration are all that can be described at present. As to the remote results further evidence will be forthcoming later on.

Even when the haemothorax is not causing actual dyspnoea, the patient is always more comfortable after the fluid has been removed, and for this reason only it is worth while to aspirate whenever possible. After aspiration the temperature may rise slightly for a day or two and then fall to normal, or it may show a decided fall; but more often it appears to be entirely uninfluenced. The following observations showed the results as regards the functional activity of the lung and the position of the heart as far as these were noted during the period in which the patients remained in France.

Haemothorax. 51 cases aspirated.

9 showed no change in physical signs of air entry when examined between the fourth and thirteenth days after injury.

34 showed improved air entry. First week 3 cases, second week 16 cases, third week 12 cases, after third week 3 cases.

2 showed much improved air entry when examined on the eighteenth and forty-third days after injury.

6 showed practically normal air entry; first week 1 case, second week 4 cases, fourth week 1 case. 
11 cases not aspirated.

8 showed no change in air entry when examined on tenth and thirty-ninth days after injury.

2 showed improved air entry, 1 in the third and 1 in the fourth week.

1 showed much improved air entry on twenty-seventh day.

60 per cent. of the aspirated cases thus showed improvement in the first three weeks, and 10 per cent. were practically normal in a fortnight. In the non-aspirated cases there were only 27 per cent. which showed any improvement in four weeks.

In the 5 cases which recovered rapidly the wounds were at the apex in 2, at the base in 2 , and in the middle of the chest in 1 (1).

In 20 cases in which the heart was displaced, as shown by physical examination, the $\mathrm{X}$-rays, or both, the following results were observed:

Right side. Average amount withdrawn, $36 \mathrm{oz}$. Heart normal in four to fifteen days in 10 cases; heart not normal in two to nino days in 4 cases.

Left side. Average amount withdrawn, 31 oz. Heart normal in 3 cases in five, twelve, and twenty days; heart not normal in 2 cases in twelve and nineteen days.

In 60 per cent. of the cases, therefore, the heart had returned to its normal position within a fortnight. In 1 case which was not aspirated the heart was normal in position in three weeks.

Pneumo-haemothorax.

Right side. In 5 cases the cardiac impulse was in the nipple line or $\frac{1}{2}$ to 1 inch outside it. In 2 cases which were aspirated the heart was normal within a fortnight, in 3 cases which were not aspirated the heart was normal in seventeen days.

Left side. In 4 cases showing much cardiac displacement to the right by $\mathrm{X}$-rays, in 1 the heart was normal in a fortnight, and in 1 in about four weeks. In the other 2 it was not normal in a fortnight. All had been aspirated.

In pneumo-haemothorax, therefore, there is not much evidence that aspiration hastens the return of the beart to its normal position.

\section{APPENDIX.}

\section{Fatal Cases.}

Case 13. Wounded 10/6/16, admitted 11/6/16 with shrapnel wound, chest. Large right-sided pneumo-haemothorax. Heart pushed over to left. Was explored twice in several places without results. 17/6/16. Rib resected and large amount of blood evacuated. Patient's temperature, which before the operation had ranged from $99^{\circ}$ to $101^{\circ}$, rose to $103^{\circ}$, and fluctuated between that and normal. The general condition became steadily worse and there was copious discharge of blood from the pleura. Died after a severe haemorrhage, $6 / 7 / 16$.

$P . M$. Fragment of shell-casing in right upper lobe. Right lung com- 
pletely collapsed and covered with purulent lymph. Right heart dilated. Fatty change in liver and kidneys. Spleen large, soft, and pale.

Case 14. Wounded 13/11/16, admitted 19/11/16. Rifle-bullet wound perforating left chest. Air and blood were passing through the entrance wound over left clavicle. T. $101.5^{\circ}$; mucopurulent sputum. Much subcutaneous emphysema over whole of left chest. 20/11/16. Luft chest explored in two places - thin brownish fluid withdrawn from one, and pus from the other. Resection of rib and drainage. Patient's condition did not improve after the operation, and he died $24 / 11 / 16$.

$P .-M$. Collapse of left lung with laceration in track of bullet. Pleura coated with purulent lymph. Early broncho-pneumonia right lung. Predominant organism in fluid withdrawn by exploring syringe was a Gram-positive diplococcus.

Case 15. Wounded 2/7/16, admitted 9/7/16. Rifle-bullet wound perforating lower part of right chest. T. $100 \cdot 2^{\circ}$. Fresh streaks of blood in sputum, signs of pneumo-haemothorax right side, pleurisy both sides. 12/7/16. Bile escaping from exit wound in back. $15 / 7 / 16$. Explored pus and blood containing anaerobic organisms. 16/7/16. Liver explored and abscess drained. One rib found to be fractured. Patient continued to discharge large quantities of bile from the wound. His stools became clay-coloured. General condition rapidly became worse. Temperature fluctuated between $103.4^{\circ}$ and $99.4^{\circ}$. Died 19/7/16.

P.-M. 26/7/16. Pleurisy both lungs. Right lobe of liver oxtensively lacerated. Gall-bladder empty. Right kianey wounded. All organs in advanced state of decomposition and with characteristic appearance of anaerobic infection.

Case 77. Wounded 10/7/16, admitted 13/7/16. Shrapnel wound perforating right chest. T. $98^{\circ}$. Signs of large right haemothorax. Heart pushed over to left. 15/7/16. Explored, blood withdrawn from which no growth was obtained. T. 101. General condition bad. 16/7/16. Right side much swollen and oedematous. Opened and drained. Patient died following night.

P.-M. 17/7/16. Ninth rib fractured in two places and parietal pleura torn. Two pints bloody fluid right chest. Lower lobe bruised and collapsed. Left chest generalized, pleurisy, whole lung adherent. Some fatty changes in liver and kidney, spleen slightly enlarged, and soft anaerobic infection.

Case 78. Wounded 14/7/16, admitted $17 / 7 / 16$, with a wound over cartilages of sixth and seventh ribs near sternum, left side. Projectile unknown. Praecordial dullness enlarged to right. Signs of large left haemothorax and right-sided pleurisy. Dyspnoea, cyanosis. T. 99.8 . 22/7/16. Aspirated $22 \mathrm{oz}$. 23/7/16. No relief of symptoms. Temperature fluctuating between $98^{\circ}$ and $101.5^{\circ}$. Attempt made to puncture pericardium, about $4 \mathrm{oz}$. of blood withdrawn. Patient became worse and died in the evening.

P.-M. 24/7/16. Fracture tip of sixth left rib. Septic pericarditis. Left pleura wounded (haemothorax). Diaphragm pierced and liver wounded. Right sero-fibrinous pleurisy. The exploring needle had passed into right ventricle, but there was no evidence of escape of blood into pericardium.

Case 125. Wounded 17/11/16, admitted 19/11/16, with shrapnel wounds on lower part right chest. Signs of small haemothorax on right side, heart normal. Foreign body localized below diaphragm by X-ray. T. 102.4. 22/11/16. Vomiting, deep jaundice, yellow discharge from wound. Temperature had ranged from $100^{\circ}$ to $104^{\circ}$. Patient died early next morning.

$P .-M .23 / 11 / 16$. Right lung early pleurisy and some bloody fluid in pleura. Liver much lacerated, foreign body in right lobe. Much haemorrhage into peritoneum. All organs in advanced state of decomposition owing to anaerobic infection. 
Case 156. Wounded 21/8/16, admitted 27/8/16. Shell wound over fourth to fifth rib cartilages close to right border of sternum, with fracture of lower right costal cartilages. Wounds of face, arms, and left thigh. Twenty-four hours after admission patient became delirious and temperature rose. The various wounds were opened up and drained, but he became worse and died, $3 / 9 / 16$.

P.-M. 4/9/16. Purulent meningitis (? from infection by wound in left cheek). Pus over pericardium and necrosis tracking down in sheath of right rectus abdominis muscle. Gas gangrene of all organs.

Case 157. Wounded 6/6/16, admitted 8/6/16, with wounds over left scapula. History of blood passed per rectum on day after injury. Slight fresh haemoptysis. General condition very fair. 11/6/16. Occasional vomiting. Temperature raised. A tarry motion. 14/6/16. No abdominal symptoms, pain in left side, no further vomiting, general condition improved. 16/6/16. Vomiting returned; much haemorrhage from rectum. Died.

$P .-M$. same day. No haemorrhage or pleurisy, slight wound of edge of left lung. Diaphragm perforated. Wound of third part of duodenum, which was firmly adherent to colon; no general peritonitis. Copious bleeding into bowel and peritoneum.

Case 158. Wounded 20/7/16, admitted 22/7/16, with extensive wounds superior maxilla, and superficial wound right elbow-joint caused by shrapnel; wound of lung over second intercostal space right side, in nipple line. Foreign body located in lung by X-rays. 31/7/16. Much foul discharge mixed with air from chest wound. No physical signs in the lung except rhonchi. 6/8/16. Opening in chest enlarged and drained. No foreign body felt. The patient got worse and died 10/8/16.

P.-M. 11/8/16. Other wounds clean. Lower part of right upper lobe and upper part right middle lobe lacerated and necrotic. Partial collapse and broncho-pneumonia of lower lobe. Small patches of purulent pleurisy. Foreign body outside pleura near angle of fifth rib, which was fractured. Fatty changes in liver and kidneys, spleen enlarged and congested.

\section{REFERENCES.}

1. Paoli, E. de, Il Morgagni, 1916, abstract in Brit. Med. Journ. Epit, 1916, ii. 6.

2. F. D. S. and C. D., Guy's Hospital Gazette, Lond., 1916, xxx. 429.

3. Menzies, J. L., Brit. Journ. Surgery, 1915-16, iii. 667.

4. Marcel Maillet, Ann. de Méd., Paris, 1916, iii. 174, abstract in Brit. Med. Journ. Epit., 1916, ii. 2.

5. Mario Sammartano, Il Morgagni, Milan, 1916, Iviii. 280, abstract in Brit. Med. Joum. Epit., 1916, ii. 14.

6. Rudolf, R. D., Quart. Journ. Med., Oxford, 1915-16, ix. 257.

7. Dolbey, R. V., Journ. Roy. Army Med. Corps, Lond., 1916, xxvii. 158.

8. Herringham, W. P., Quart. Journ. Med., Oxford, 1916-17, x. 79. 